\title{
Introduction to the Special Section on Executive Functions and Externalizing Symptoms
}

\author{
Michael J. Sulik ${ }^{1}$ \\ Published online: 9 October 2017 \\ (C) Springer Science+Business Media, LLC 2017
}

Executive functions (EFs) refer to a set of diverse, higherorder cognitive skills that includes inhibitory control, cognitive flexibility, updating information in working memory, error monitoring, sustaining attention, and planning. EFs support goal-directed behavior and are believed to play a crucial role in self-regulation of behavior and emotions. It should, therefore, be no surprise that EFs are related to outcomes in diverse domains of functioning that include psychopathology, physical health, academic achievement, career success, and close relationships (Diamond 2013).

Because of their importance for "success in life," EFs (and self-regulation as a broader construct) have become a major topic of research. EFs have been of particular interest because a number of studies indicate that they are malleable: family and school based interventions have both shown promise for improving EFs, particularly for children with lower initial skills (Blair and Raver 2014; Diamond and Lee 2011; Schmitt et al. 2015). A large body of research has shown that EFs are consistent correlates of externalizing symptoms among both children and adults (Ogilvie et al. 2011; Schoemaker et al. 2013). Given the robust association between EFs and externalizing symptoms and the high societal costs of externalizing psychopathology, EFs have emerged as a promising target for prevention efforts.

To fulfill this promise, however, researchers need to move beyond merely documenting associations between EFs and externalizing symptoms. We have reached a point where more nuanced questions are needed to advance the field. For

Michael J. Sulik

michael.sulik@stanford.edu

1 Stanford University, 485 Lasuen Mall, Stanford, CA 94305, USA example, how much do EFs contribute to change in externalizing symptoms over time? Despite high rates of cooccurrence among externalizing disorders (Krueger and Markon 2006), are EFs more strongly related to certain types of externalizing disorders? If so, why? What mediating mechanisms can account for the relations between EFs and externalizing symptoms? Answering these questions is necessary for designing effective prevention and treatment programs. The papers in this special section help move us towards this goal by addressing questions about the mediators, moderators, and prediction of longitudinal change for the relations between EFs and externalizing symptoms.

As previously noted, EFs are positively related to success in many different domains of functioning. Yet as research on EFs has matured, investigators have adopted a greater focus on specificity, splitting the larger constructs into subdomains. For example, meta-analytic studies suggest that inhibitory control is more strongly related to math than to reading performance (Allan et al. 2014), whereas the relation between cognitive flexibility and these two academic subdomains does not appear to differ (Yeniad et al. 2013). In this special section, Huang-Pollock et al. (2017) and Lonigan et al. (2017) both investigate questions about the degree to which EFs are associated with externalizing symptoms "in general" as well as specific subtypes of externalizing symptoms such as inattention, hyperactivity, and oppositional behavior.

Huang-Pollock et al. (2017) examine relations between working memory (a specific EF skill) and internalizing and externalizing symptoms. Many epidemiological studies have described high rates of co-occurrence between externalizing and internalizing disorders (e.g., Angold et al. 1999), but explaining why these two types of disorders frequently occur together has proven to be more challenging. Huang-Pollock et al. (2017) addresses this question by using a bi-factor 
model. This is a sophisticated statistical modeling technique that can be used to separate subdomains of symptomatology from a general factor that captures the overlap among these subdomains. This approach recognizes the complexity of psychopathology as it occurs in real-world contexts: externalizing disorders often co-occur with one another, and with internalizing symptoms such as anxiety and depression. Being able to separate these components can help address the possibility of confounding.

Huang-Pollock et al. (2017) use this model to predict a factor corresponding to the overlap between internalizing and externalizing symptoms separately from factors that are specific to each symptom domain. They found the EFs were associated with the overlap and with the externalizing-specific factor, but not with the internalizing-specific factor. These results suggest that EFs can help explain why internalizing and externalizing disorders co-occur, and further indicate that the association between EFs and internalizing symptoms may be spurious, an artifact of the much stronger relation between EFs and externalizing symptoms.

Lonigan et al. (2017) also use the bi-factor model to test children's language ability and EFs in preschool as predictors of elementary school externalizing symptoms. An important finding from this study was that gender moderated these relations: the association between language ability and a factor specific to inattention and hyperactivity was greater for girls, whereas the association between EFs and a general externalizing symptom factor was greater for boys. Although there are large gender disparities in the prevalence of externalizing disorders, the role of gender as a moderating influence is less clear and merits further attention.

A second contribution of papers in this special section is the use of longitudinal data to examine change in symptoms. The study of externalizing symptoms has been strongly influenced by developmental theories (Moffitt 1993) and modeling approaches (Nagin and Tremblay 2005). Understanding patterns of change over time is a much more challenging endeavor than simply examining cross-sectional relations. This is especially true for externalizing symptoms, which exhibit remarkably high rank order stability across childhood (Calkins et al. 2007). The search for variables that are causally related to externalizing symptoms is difficult, and longitudinal studies - especially those that include mediation and moderation analyses - represent one step towards developing hypotheses about causal relations that can be tested experimentally. Prior research suggests that children exhibit normative decreases in aggression and oppositional behavior across childhood (Bongers et al. 2004; NICHD Early Child Care Research Network 2004), but that children whose symptoms persist engage in behaviors that progressively escalate in severity (Loeber and Burke 2011). Identifying predictors of persistence and desistence in externalizing symptomatology is crucial for diverting children from this harmful developmental pathway.

Van Dijk et al. (2017) focus on the associations between expressed emotion during parent-child interaction, investigating EFs as a mediator between dyadic emotional reactivity and children's subsequent externalizing symptoms. This study is notable for three reasons. First, the use of dynamical systems theory to examine dyadic states is a valuable contribution: it acknowledges that parenting is not merely a top-down process; rather, parents and children are mutually influential actors who both influence the quality of their interactions. The second contribution of this study is that it considers the role of a third variable (environmental influences) as a contributor to both EFs and externalizing behavior problems. Moreover, the use of longitudinal data in this study with controls for stability in symptoms helps us understand the degree to which EFs may contribute to change in externalizing symptoms: by providing information about the size of the indirect effect of parent-child interaction quality on child externalizing symptoms through EFs, the longitudinal design used in this study gives useful data about the potential impact of parenting interventions on both EFs and externalizing symptoms.

Also using a longitudinal study design in which they controlled for early symptoms, Waller et al. (2017) investigate whether the interaction between callous and unemotional behaviors and EFs in early childhood predicts change in symptoms between three and ten years of age. In this study, strong EFs blunted the positive relation between callous and emotional behaviors and change in multiple aspects of externalizing symptoms that included reactive, proactive, and relational aggression, as well as peer liking. This study suggests that, rather than producing "skilled psychopaths," EFs can be an important protective factor for children who are at risk for externalizing psychopathology due to their callous and unemotional behaviors. Understanding how multiple child characteristics work together to influence symptom development is crucial for identifying individuals who would benefit most from prevention and intervention efforts.

The studies in this special section illustrate how externalizing symptoms are shaped by a constellation of child characteristics and environmental influences. They do not shy away from a complex and nuanced view of the factors that contribute to externalizing symptoms. These studies are illustrative of the path forward for understanding the development of these symptoms. At the same time, these four studies represent only a small sample of explanatory variables. Notably absent are studies addressing the biological bases of externalizing behavior, which should also be considered as an important predictive factor that may also function as a moderator or mediator. 


\section{Compliance with Ethical Standards}

Conflict of Interest The author declares that he has no conflict of interest.

\section{References}

Allan, N. P., Hume, L. E., Allan, D. M., Farrington, A. L., \& Lonigan, C. J. (2014). Relations between inhibitory control and the development of academic skills in preschool and kindergarten: A meta-analysis. Developmental Psychology, 50, 2368-2379. https://doi.org/10. 1037/a0037493.

Angold, A., Costello, E. J., \& Erkanli, A. (1999). Comorbidity. Journal of Child Psychology and Psychiatry, 40, 57-87. https://doi.org/10. 1111/1469-7610.00424.

Blair, C., \& Raver, C. C. (2014). Closing the achievement gap through modification of neurocognitive and neuroendocrine function: Results from a cluster randomized controlled trial of an innovative approach to the education of children in kindergarten. PLoS One, 9, e112393. https://doi.org/10.1371/journal.pone.0112393.

Bongers, I. L., Koot, H. M., van der Ende, J., \& Verhulst, F. C. (2004). Developmental trajectories of externalizing behaviors in childhood and adolescence. Child Development, 75, 1523-1537. https://doi. org/10.1111/j.1467-8624.2004.00755.x.

Calkins, S. D., Blandon, A. Y., Williford, A. P., \& Keane, S. P. (2007). Biological, behavioral, and relational levels of resilience in the context of risk for early childhood behavior problems. Development and Psychopathology, 19, 675-700. https://doi.org/10.1017/ S095457940700034X.

Diamond, A. (2013). Executive functions. Annual Review of Psychology, 64, 135-168. https://doi.org/10.1146/annurev-psych-113011143750

Diamond, A., \& Lee, K. (2011). Interventions shown to aid executive function development in children 4 to 12 years old. Science, 333, 959-964. https://doi.org/10.1126/science.1204529.

van Dijk, R., Deković, M., Bunte, T. L., Schoemaker, K., ZondervanZwijnenburg, M., Espy, K. A., \& Matthys, W. (2017). Mother-child interactions and externalizing behavior problems in preschoolers over time: Inhibitory control as a mediator. Journal of Abnormal Child Psychology. https://doi.org/10.1007/s10802-016-0258-1.

Huang-Pollock, C., Shapiro, Z., Galloway-Long, H., \& Weigard, A. (2017). Is Poor Working Memory a Transdiagnostic Risk Factor for Psychopathology? Journal of Abnormal Child Psychology. https://doi.org/10.1007/s10802-016-0219-8.

Krueger, R. F., \& Markon, K. E. (2006). Reinterpreting comorbidity: A model-based approach to understanding and classifying psychopathology. Annual Review of Clinical Psychology, 2, 111133. https://doi.org/10.1146/annurev.clinpsy.2.022305.095213.

Loeber, R., \& Burke, J. D. (2011). Developmental pathways in juvenile externalizing and internalizing problems. Journal of Research on Adolescence, 21, 34 46. https://doi.org/10.1111/j.1532-7795.2010. 00713.x.

Lonigan, C. J., Spiegel, J. A., Goodrich, J. M., Morris, B. M., Osborne, C. M., Lerner, M. D., \& Phillips, B. M. (2017). Does preschool selfregulation predict later behavior problems in general or specific problem behaviors? Journal of Abnormal Child Psychology. https://doi.org/10.1007/s10802-016-0260-7.

Moffitt, T. E. (1993). Adolescent-limited and life-course-persistent antisocial behavior: A developmental taxonomy. Psychological Review, 100, 674-701. https://doi.org/10.1037/0033-295X.100.4.674.

Nagin, D. S., \& Tremblay, R. E. (2005). What has been learned from group-based trajectory modeling? Examples from physical aggression and other problem behaviors. The Annals of the American Academy of Political and Social Science, 602, 82-117. https://doi. org/10.1177/0002716205280565.

NICHD Early Child Care Research Network. (2004). Trajectories of physical aggression from toddlerhood to middle childhood: Predictors, correlates, and outcomes. Monographs of the Society for Research in Child Development, 69(4), vii-129.

Ogilvie, J. M., Stewart, A. L., Chan, R. C., \& Shum, D. H. (2011). Neuropsychological measures of executive function and antisocial behavior: A meta-analysis. Criminology, 49, 1063-1107. https://doi. org/10.1111/j.1745-9125.2011.00252.x.

Schmitt, S. A., McClelland, M. M., Tominey, S. L., \& Acock, A. C. (2015). Strengthening school readiness for Head Start children: Evaluation of a self-regulation intervention. Early Childhood Research Quarterly, 30, 20-31. https://doi.org/10.1016/j.ecresq. 2014.08.001.

Schoemaker, K., Mulder, H., Deković, M., \& Matthys, W. (2013). Executive functions in preschool children with externalizing behavior problems: A meta-analysis. Journal of Abnormal Child Psychology, 41, 457-471. https://doi.org/10.1007/s10802-0129684-x.

Waller, R., Hyde, L. W., Baskin-Sommers, A. R., \& Olson, S. L. (2017). Interactions between callous unemotional behaviors and executive function in early childhood predict later aggression and lower peerliking in late-childhood. Journal of Abnormal Child Psychology, 45, 597-609. https://doi.org/10.1007/s10802-016-0184-2.

Yeniad, N., Malda, M., Mesman, J., van IJzendoorn, M. H., \& Pieper, S. (2013). Shifting ability predicts math and reading performance in children: A meta-analytical study. Learning and Individual Differences, 23, 1-9. https://doi.org/10.1016/j.lindif.2012.10.004. 